\title{
Direitos fundamentais: da constituição às políticas públicas
}

Bruno Santos Cunha ${ }^{1}$

\section{Resumo}

O presente trabalho tem o objetivo de analisar a concretização dos direitos fundamentais - sobretudo os sociais -constitucionalmente assegurados pela via da implementação das chamadas políticas públicas. Para tal, busca-se um trilhar histórico capaz de subsidiar o entendimento da normatividade e eficácia social dos direitos fundamentais, chegando-se - por meio de contextualização histórica - ao papel estatal prestacional em tal atuação, como forma de alcance efetivo da ordem social justa, cuja previsão, com nítido viés dirigente, é extraída do próprio texto constitucional.

Palavras-chave: Direitos fundamentais. Constituição. Políticas públicas.

\section{Normatividade e eficácia dos direitos fundamentais}

A afirmação histórica dos direitos fundamentais nas constituições contemporâneas é inconteste e em conjunto com os princípios da soberania, da participação popular e da separação de poderes, entre outros, apresenta-se como uma das bases dos atuais pactos constitucionais.

Dessa forma, há de se dizer que grande parte das discussões atuais acerca do alcance objetivo e material do Estado Social - o qual notadamente se vislumbra na caracterização do Estado brasileiro, por exemplo - tem como alvo a aplicabilidade e eficácia das normas relativas aos direitos fundamentais, uma vez que, conforme salienta Ingo Sarlet:

1 Procurador do Município do Recife. Ex-professor do Curso de Direito da Universidade Federal de Santa Catarina. Advogado e Professor Universitário. 
No âmbito de um Estado social de Direito - e o consagrado pela nossa evolução constitucional não foge à regra os direitos fundamentais sociais constituem exigência inarredável do exercício efetivo das liberdades e garantia da igualdade de chances (oportunidades), inerentes a noção de uma democracia e um Estado de Direito de conteúdo não meramente formal, mas, sim, guiado pelo valor da justiça material. $^{2}$

O tema remonta à montagem e estruturação do Estado Social e, da mesma forma, à formulação de um constitucionalismo social que suplante a ordem estritamente liberal-individualista do Estado Liberal, segundo a qual não competia ao Estado um papel central de guia da sociedade civil para a realização de fins comuns. Comparato assinala, ainda, que, para o Estado Liberal, "a grande, senão única, tarefa estatal consiste em propiciar, sob a égide de leis gerais, constantes e uniformes, condições de segurança - física e jurídica - à vida individual". ${ }^{3}$

No contexto liberal, a estipulação dos chamados direitos de defesa contra interferências ilegítimas do Estado consegue transparecer, de maneira muito mais nítida, uma caracterização jurídica, de modo a configurar uma aplicação imediata dos direitos reconhecidos ante o Estado que, em tais casos, deve se abster de determinadas atuações a fim de não adentrar na esfera de liberdade e autonomia pessoal do indivíduo.

Entrementes, com o advento do constitucionalismo social, isto é, com a concepção de uma finalidade constitucional consubstanciada no alcance material de um fim comum e baseado nos valores da pessoa humana, na construção de uma vida digna e na direção da coletividade para o alcance de metas predeterminadas, abre-se espaço para uma formulação muito mais ampla de Estado, que agora deve se pautar, prioritariamente, pelo desenvolvimento comum e pela justiça social.

Ante tais objetivos, todo o centro de atividades estatais deve ser repensado, impondo-se um total reexame, já que, obviamente, com o Estado Social de Direito,

2 SARLET, Ingo Wolfgang. A eficácia dos direitos fundamentais. 3. ed. rev. atual. ampl. Porto Alegre: Livraria do Advogado, 2003. p. 67-68.

3 COMPARATO, Fábio Konder. Ensaio sobre o juízo de constitucionalidade de políticas públicas. Revista dos Tribunais, São Paulo, ano 86, v. 737, p. 11-22, mar. 1997. 
a "reorganização da atividade estatal em função de finalidades coletivas torna-se indispensável". ${ }^{4}$ Bem de ver, pois, que a "atribuição prioritária dos Poderes Públicos torna-se, neste Estado, a progressiva constituição de condições básicas para o alcance da igualdade social entre todos os grupos, classes e regiões do país."

Todo modo, tem-se claro que o caráter social que se vislumbra nesse novo modelo de Estado se encontra determinado pelos programas de ação estabelecidos para o alcance do desenvolvimento e da justiça social, isto é, pelas formas de atuação positiva (prestacional) escolhidas pelo Estado, no âmbito constitucional, para a consecução de seus objetivos, configurando assim grande parte dos já aludidos direitos sociais. Nesse sentido, vale a colocação de Gilmar Mendes sobre os já mencionados direitos a prestações, salientando que:

[...] vinculados à concepção de que ao Estado incumbe, além da não-intervenção na esfera da liberdade pessoal dos indivíduos, garantida pelos direitos de defesa, a tarefa de colocar à disposição os meios materiais e implementar as condições fáticas que possibilitem o efetivo exercício das liberdades fundamentais, os direitos fundamentais a prestações objetivam, em última análise, a garantia não apenas da liberdade-autonomia (liberdade perante o Estado), mas também da liberdade por intermédio do Estado, partindo da premissa de que o individuo, no que concerne à conquista e manutenção de sua liberdade, depende em muito de uma postura ativa dos poderes públicos. ${ }^{6}$

Ter-se-ia com tais direitos, então, uma veiculação de programas constitucionais referentes, sobretudo, à promoção da justiça social.

Ainda no tema, ressalta-se que a proposição constitucional de direitos sociais como programas governamentais a serem instaurados acabou por conceber

4 COMPARATO, Fábio Konder. Ensaio sobre o juízo de constitucionalidade de políticas públicas. Revista dos Tribunais, São Paulo, ano 86, v. 737, p. 11-22, mar. 1997.

5 COMPARATO, Fábio Konder. Ensaio sobre o juízo de constitucionalidade de políticas públicas. Revista dos Tribunais, São Paulo, ano 86, v. 737, p. 11-22, mar. 1997. p. 16.

6 MENDES, Gilmar Ferreira. Direitos fundamentais e controle de constitucionalidade. 3. ed. São Paulo: Saraiva, 2004. p. 6. 
uma categoria normativa que, em princípio, tinha sua aplicabilidade fortemente ligada a fatores políticos, uma vez que tais direitos não tinham a aplicabilidade direta e imediata característica dos direitos de liberdade proclamados com o constitucionalismo liberal.

Para, além disso, a falta de um nítido conceito jurídico para os direitos sociais acabava por dificultar sua implementação e se transformava em um refúgio político para os governantes, a ponto de se dizer que a programaticidade furtava a normatividade de tais direitos e, ato contínuo, sua eficácia e aplicação prática.

Assim, embora não possam ser vistas da mesma forma que nos direitos de liberdade - de nítida aplicabilidade imediata - as normas definidoras de direitos sociais, ainda que programáticas, devem ser lidas e aperfeiçoadas em consonância com as finalidades e objetivos do Estado Social que, em sua gênese, suplanta a tendência de se entender os direitos individuais como contrapostos aos direitos sociais, já que tais direitos compõem um todo harmônico que sintetiza a possibilidade democrática e libertária com a qual se afigura essa forma de Estado.

Denota-se, então, que só o fato da positivação constitucional dos direitos fundamentais não é capaz de instaurar um regime de aplicação material das referidas normas, uma vez que, no dizer de Bonavides:

O Estado de direito do constitucionalismo social precisa de absorver a programaticidade das normas constitucionais. Atribuindo-se eficácia vinculante à norma programática, pouco importa que a Constituição esteja ou não repleta de proposições desse teor, ou seja, de regras relativas a futuros comportamentos estatais. O cumprimento dos cânones constitucionais pela ordem jurídica terá dado um largo passo à frente. Já não será fácil com respeito à Constituição tergiversar-lhe a aplicabilidade e eficácia das normas como os juristas abraçados à tese antinormativa, os quais, alegando programaticidade de conteúdo, costumam evadirse ao cumprimento ou observância de regras e princípios constitucionais. ${ }^{7}$

BONAVIDES, Paulo. Curso de direito constitucional. 18. ed. São Paulo: Malheiros, 2006. p. 237. 
E continua o aludido autor ao afirmar que:

O problema do constitucionalismo contemporâneo, no presente quadro interpretativo das flutuações doutrinárias sobre o caráter de normatividade das Constituições, se concentra principalmente em determinar o caráter jurídico ou não das normas programáticas e sobretudo o grau de eficácia e aplicabilidade de todas as normas da Constituição. ${ }^{8}$

Nesse tocante, tem-se que os objetivos e finalidades que devem ser buscados pelo moderno Estado Social são também elencados no corpo constitucional com forma programática, indicando um rumo para a adoção das políticas sociais. Assim:

Escusa lembrar que tais objetivos são juridicamente vinculantes para todos os órgãos do Estado e também para todos os detentores de poder econômico ou social, fora do Estado. A juridicidade das normas que simplesmente declararam tais fins [...], ou que impõem a realização de determinado programa de atividades - as normas propriamente programáticas -, já não pode ser posta em dúvida nesta altura da evolução jurídica. ${ }^{9}$

De fato:

Se o Estado está constitucionalmente obrigado a prover tais demandas, cabe indagar se, e em que medida, as ações com o propósito de satisfazer tais pretensões podem ser juridicizadas, isto é, se, e em que medida, tais ações se deixam vincular juridicamente. ${ }^{10}$

Por fim, não há dúvidas que a aplicabilidade imediata e a juridicidade dos direitos fundamentais devem ser vistas como regra e princípio basilar na construção da justiça social que se pretende com a formatação do Estado Democrático e Social de Direito, ressaltando-se que a atuação promocional realizada pelo ente

8 BONAVIDES, Paulo. Curso de direito constitucional. 18. ed. São Paulo: Malheiros, 2006. p. 236.

9 COMPARATO, Fábio Konder. Ensaio sobre o juízo de constitucionalidade de políticas públicas. Revista dos Tribunais, São Paulo, ano 86, v. 737, p. 11-22, mar. 1997. p. 19.

${ }^{10}$ MENDES, Gilmar Ferreira. Direitos fundamentais e controle de constitucionalidade. 3. ed. São Paulo: Saraiva, 2004. p. 7. 
estatal com vistas à justiça social passa pela adoção e controle das políticas públicas que venham a colocar em prática os direitos constitucionalmente reconhecidos, uma vez que a justiciabilidade de tais direitos deve ser entendida como mecanismo de proteção aos mesmos, para além da - e em complemento - possível implementação prática dos mesmos pela via executiva ou legislativa.

\section{Conceito e arcabouço jurídico das políticas públicas}

De toda sorte, vê-se que a realização das necessidades conjugadas como coletivas e sociais para que o atual Estado Social tenha sucesso tem como critério central e informador a implementação das chamadas políticas públicas. Por certo, então, passamos à discussão acerca desse novo conceito a ser introduzido na teoria jurídica e, ademais, nas teorias constitucionais. Bucci trabalha o conceito de 'políticas públicas' como:

Programas de ação governamental visando a coordenar os meios à disposição do Estado e as atividades privadas, para a realização de objetivos socialmente relevantes e politicamente determinados. Políticas públicas são 'metas coletivas conscientes' e, como tais, um problema de direito público, em sentido lato. ${ }^{11}$

Na mesma esteira, Comparato aponta Ronald Dworkin como pioneiro dos autores contemporâneos a utilizar o conceito de política como 'meta a alcançar' e como programa de melhoria econômica, política ou social da comunidade. E continua o aludido autor ao traçar a separação entre políticas e princípios, vez que a primeira tende a estabelecer uma finalidade coletiva e o segundo, um direito individual. ${ }^{12}$

Na mesma esteira, Pizzolati salienta que:

\footnotetext{
${ }^{11}$ BUCCI, Maria Paula Dallari. Direito administrativo e políticas públicas. São Paulo: Saraiva, 2002. p. 241.

${ }^{12}$ COMPARATO, Fábio Konder. Ensaio sobre o juízo de constitucionalidade de políticas públicas. Revista dos Tribunais, São Paulo, ano 86, v. 737, p. 11-22, mar. 1997.
} 
[...] política pública pode ser definida como atividade administrativa baseada em orientação geral, inserida na função de planejamento, que visa, intervindo na ordem social, a alcançar, mediante decisões, atos executivos e procedimentos administrativos, determinados objetivos de longo prazo, estipulados em normas-objetivo ou diretrizes normativas. ${ }^{13}$

Ter-se-ia, ante tais definições, que a política pública não é uma norma ou um ato específico, já que engloba esses dois conceitos e se caracteriza como uma atividade tendente à realização de um objetivo que, sobretudo, se consubstancia em uma prática estatal com o intuito de dar efetividade aos direitos fundamentais e assim viabilizar o viés de justiça social que se apresenta no Estado Social, já que pouco vale o mero reconhecimento formal de direitos se não existem os instrumentos que os efetivem. ${ }^{14}$

Importante notar também que o referencial da adoção das políticas públicas perpassa a implementação de direitos sociais e pode ser notado em qualquer que seja o modelo ideológico adotado pelo Estado, já que:

A política pública do Estado será fundamental e determinante, pois, mesmo em um Estado que pretende a preponderância do livre-mercado e da iniciativa privada, a política pública relativa à área econômica deverá cuidar para que a livre concorrência impere, para que não haja inflação, nem descontrole cambial e haja o crescimento da produção. ${ }^{15}$

Assim, mesmo que se pense em um modelo de Estado não intervencionista e que não adote uma política prestacional e promocional de direitos fundamentais sociais, há de se ressaltar a necessidade da adoção de políticas públicas que ao menos possam garantir, regular e fiscalizar as iniciativas privadas e o livre-mercado. Um exemplo de tal realidade, no Brasil, se dá com a criação de agências reguladores

${ }^{13}$ PIZZOLATTI, Rômulo. O controle jurisdicional do mérito na atividade administrativa. 2001. 172 f. Tese (Doutorado)-Centro de Ciências Jurídicas, Universidade Federal de Santa Catarina, Florianópolis, 2001.

${ }^{14}$ FREIRE JÚNIOR, Américo Bedê. O controle judicial de políticas públicas. São Paulo: Revista dos Tribunais, 2005. p. 48.

${ }^{15}$ FRISCHEISEN, Luiza Cristina Fonseca. Políticas públicas: a responsabilidade do administrador e o ministério público. São Paulo: M. Limonad, 2000. p. 80. 
com poder de polícia para fiscalizar setores como o telefônico, de aviação civil, de combustíveis e outros. ${ }^{16}$ Entrementes, é no contexto das políticas públicas referentes à concretização de uma ordem social justa que se estrutura o presente trabalho.

Ressai desse contexto, pois, a utilização do termo 'políticas públicas' como programa de ação governamental consistente em um conjunto estruturado de normas e atos com finalidade predeterminada. Disso decorre a necessidade de se pensar, cada vez mais, o horizonte jurídico atrelado à esfera política, traçando laços entre tais patamares que ensejem a criação e formatação de um subsistema que verdadeiramente possa administrar a implementação das referidas políticas de acordo com os ditames teórico-constitucionais.

É nesse ponto do trabalho que emerge a necessidade de alçar as políticas públicas a um local de destaque dentro do esquema burocrático de poder, conferindo a elas um estudo pormenorizado capaz de instrumentalizar sua adoção. Nessa seara, o Direito Administrativo torna-se o ponto de partida para a releitura proposta a fim de determinar a prevalência do interesse público e coletivo, já que ele não mais pode ser enxergado como um sistema de vetos à atividade do Estado - em uma leitura cruzada com a primeira dimensão de direitos outrora aludida:

[...] mas precisa ser adequadamente descrito não como o arranjo que garante a liberdade do cidadão comum e dos pequenos, senão como o arranjo político pelo qual a grande política do Estado, as grandes finanças e os grandes negócios repartem entre si suas esferas de competência e liberdade. ${ }^{17}$

Em outras palavras, é preciso que o referencial teórico do Direito Administrativo seja deslocado do ato administrativo para a política pública, ou seja, o princípio basilar dessa disciplina deve ser assentado não mais na não intervenção do Estado Liberal na esfera privada do particular, mas na atuação do ente estatal congruente com a normatividade que decorre da Constituição e a consequente construção social justa.

${ }^{16}$ FRISCHEISEN, Luiza Cristina Fonseca. Políticas públicas: a responsabilidade do administrador e o ministério público. São Paulo: M. Limonad, 2000. p. 80.

${ }^{17}$ BUCCI, Maria Paula Dallari. Direito administrativo e políticas públicas. São Paulo: Saraiva, 2002. p. 11. 


\section{A administração pública e as políticas públicas}

A superioridade da lei sobre todas as outras manifestações de atividade do Estado é nítida na configuração do Estado constitucional liberal clássico. Nesse contexto, a expressão do poder e da soberania popular era reconhecida no Poder Legislativo, o qual, representando o povo por excelência, afigurava-se como um poder superior aos demais.

Comparato assinala ainda que, diante de tal realidade:

Aos demais Poderes - o Executivo propriamente dito, na parte administrativa, e o Judiciário em caso de conflito de interesses - cabe a mera execução das normas legais, sem nenhuma iniciativa ou impulso próprio. O constitucionalismo liberal consagrou em cheio esse paradigma de Estado Legislativo. ${ }^{18}$

Todavia, a estruturação de um Estado que elenca entre seus princípios fundantes uma finalidade notadamente marcada pela construção de uma ordenação social mais justa - sobretudo por meio de uma postura promocional em relação aos direitos fundamentais, como ocorre com o atual modelo do Estado Social -, acaba por fortalecer a função planejadora e executiva do Estado. Assim é que Comparato alude que:

Quando, porém, a legitimidade do Estado passa a fundarse, não na expressão legislativa da soberania popular, mas na realização de finalidades coletivas, a serem concretizadas programadamente, o critério classificatório das funções e, portanto, dos Poderes estatais só pode ser o das políticas públicas ou programas de ação governamental. E aí, à falta de uma conseqüente reorganização constitucional de Poderes, a qual dê preeminência à função planejadora, que ordena estrategicamente as múltiplas atividades estatais, é ao Governo, impropriamente chamado agora Poder Executivo, que incumbe o papel hegemônico. ${ }^{19}$

${ }^{18}$ COMPARATO, Fábio Konder. Ensaio sobre o juízo de constitucionalidade de políticas públicas. Revista dos Tribunais, São Paulo, ano 86, v. 737, p. 11-22, mar. 1997.

${ }^{19}$ COMPARATO, Fábio Konder. Ensaio sobre o juízo de constitucionalidade de políticas públicas. Revista dos Tribunais, São Paulo, ano 86, v. 737, p. 11-22, mar. 1997. 
Denota-se então que a lei, na estrutura de um Estado Social dirigente, acaba por perder a sua primazia na expressão da soberania popular e se transforma em um mero instrumento de governo. O fato é que, ante tal contexto, ganha força a Administração Pública como o ente que expressa não apenas a lei, mas o Direito enquanto todas as normas do ordenamento jurídico e as finalidades constitucionalmente reconhecidas e adotadas pelo Estado.

A Administração Pública, no contexto do Estado Social, não mais se limita à função de polícia administrativa consubstanciada em um sistema de controle e vetos ao próprio Estado, mas traz para si a função de promover e prestar os serviços públicos essenciais para o desenvolvimento social. Bem de ver, pois, que a Administração Pública e, por conseguinte, o administrador:

[...] está vinculado à Constituição e à implementação das políticas públicas da ordem social (quer diretamente quer em parceria com a sociedade civil - nesse sentido atuando também como fiscalizador), estando adstrito às finalidades explicitadas na Constituição, bem como nas leis integradoras, e não cumpri-las caracteriza omissão, passível de responsabilidade. Essa obrigação de cumprir as normas constitucionais da ordem social insere-se no devido processo legal que deve ser obedecido pela Administração, na implementação das políticas públicas. ${ }^{20}$

Assim, importante para a redefinição da atuação da Administração na implementação das políticas públicas se afigura o entendimento de suas características básicas e seus princípios norteadores no atual modelo de constitucionalismo social, conforme se verá a seguir.

\subsection{Os princípios norteadores da administração pública}

Além de estatuir em seu artigo inaugural os princípios fundamentais do Estado democrático de direito brasileiro, a Constituição da República Federativa do

\footnotetext{
${ }^{20}$ FRISCHEISEN, Luiza Cristina Fonseca. Políticas públicas: a responsabilidade do administrador e o ministério público. São Paulo: M. Limonad, 2000. p. 91.
} 
Brasil de 1988, em seu artigo $3^{\circ}$, estabelece os objetivos fundamentais da República Federativa do Brasil, veja-se:

Art. $3^{\circ}$. Constituem objetivos fundamentais da República Federativa do Brasil:

I - construir uma sociedade livre, justa e solidária;

II - garantir o desenvolvimento nacional;

III - erradicar a pobreza e marginalização e reduzir as desigualdades sociais e regionais;

IV - promover o bem de todos, sem preconceitos de origem, raça, sexo, cor, idade e quaisquer outras formas de discriminação. ${ }^{21}$

Torna-se claro, ante tal assertiva, que todas as esferas de poder político dentro do Estado devem se pautar pela consecução desses objetivos, cada qual dentro de seu espectro de atuação. De tal maneira, estar-se-ia diante da configuração de um legítimo interesse público nos momentos em que a atuação estatal fosse pautada pelo alcance e obtenção do ideário supramencionado.

Bem de ver, então, que a Administração Pública pode ser definida como o conjunto de meios institucionais, materiais, financeiros e humanos, organizados sob a égide e autoridade do Governo e preordenados à execução das decisões políticas destinadas a assegurar as múltiplas tarefas de interesse geral que incumbem ao Estado. ${ }^{22}$ Enquanto tal, deve trilhar sua atividade, assim como toda atuação estatal, de acordo com o interesse público, que, no dizer de Celso Antônio Bandeira de Mello:

[...] nada mais é que a dimensão pública dos interesses individuais, ou seja, dos interesses de cada indivíduo enquanto partícipe da Sociedade [...]

[...] deve ser conceituado como o interesse resultante do conjunto dos interesses que os indivíduos pessoalmente têm quando considerados em sua qualidade de membros da Sociedade e pelo simples fato de o serem. ${ }^{23}$

\footnotetext{
${ }^{21}$ Constituição da República Federativa do Brasil de 5 de outubro de 1988, art. 3º

22 SILVA, José Afonso da. Curso de direito constitucional positivo. 22. ed. rev. atual. São Paulo: Malheiros, 2003. p. 635.

${ }^{23}$ MELLO, Celso Antônio Bandeira de. Curso de direito administrativo. 18. ed. São Paulo: Malheiros, 2005. p. 52-53.
} 
O interesse público, como visto, deve definir o rumo de atuação da Administração, fazendo com que, segundo Bandeira de Mello, a indisponibilidade de tal interesse pela Administração configure as 'pedras de toque' do regime jurídico-administrativo. ${ }^{24}$ Outrossim, há de se mencionar que "a Administração não titulariza interesses públicos. O titular deles é o Estado, que, em certa esfera, protege e exercita através da função administrativa”. ${ }^{25}$

De tal maneira, a supremacia do interesse público sobre o privado deve ser entendida, pois, como a posição privilegiada que o órgão encarregado de zelar pelo interesse público e de exprimi-lo deve sustentar nas relações com os particulares e, ademais, a supremacia do referido órgão nas mesmas relações. Já a indisponibilidade do interesse público se perfaz no sentido de que a lei e as próprias exigências do bem comum impedem que a Administração se afaste do cumprimento das finalidades públicas. ${ }^{26}$

Tais princípios informariam, sem margem de dúvida, toda a atuação administrativa e, ato contínuo, formariam a base para todos os demais princípios subordinados aplicáveis ao campo da Administração Pública, nos termos do caput do artigo 37 da Constituição (legalidade, impessoalidade, moralidade, publicidade e eficiência), mormente em se tratando da concretização de direitos fundamentais pela via das políticas públicas - sempre implementadas com espeque nesse viés princípio lógico e com fundamento no interesse público.

\section{A discricionariedade administrativa}

Vistas as bases que hão de nortear a atuação administrativa em seu múnus concretizador de direitos - sobretudo por meio das já aludidas políticas públicas

\footnotetext{
${ }^{24}$ MELLO, Celso Antônio Bandeira de. Curso de direito administrativo. 18. ed. São Paulo: Malheiros, 2005. p. 47.

${ }^{25}$ MELLO, Celso Antônio Bandeira de. Curso de direito administrativo. 18. ed. São Paulo: Malheiros, 2005. p. 65.

${ }^{26}$ MELLO, Celso Antônio Bandeira de. Curso de direito administrativo. 18. ed. São Paulo: Malheiros, 2005. p. 60-66.
} 
-, há de se discutir os pormenores de tal atuação, de forma a garantir aquilo que estabelecido no bojo constitucional, isto é, a construção da ordem social justa.

Uma primeira distinção a ser feita na atuação administrativa é a que se refere aos atos vinculados e aos atos discricionários. Celso Antônio Bandeira de Mello diferencia essas duas modalidades de atos salientando que:

Atos vinculados seriam aqueles em que, por existir prévia e objetiva tipificação legal do único possível comportamento da Administração em face da situação igualmente prevista em termos de objetividade absoluta, a Administração, ao expedi-los, não interfere com apreciação subjetiva alguma.

Atos 'discricionários', pelo contrário, seriam os que a Administração pratica com certa margem de liberdade de avaliação ou decisão segundo critérios de conveniência e oportunidade formulados por ela mesma, ainda que adstrita à lei reguladora da expedição deles. ${ }^{27}$

E continua o aludido autor ao estabelecer um conceito de discricionariedade:

Discricionariedade, portanto, é a margem de liberdade que remanesça ao administrador para eleger, segundo critérios consistentes de razoabilidade, um, dentre pelo menos dois comportamentos cabíveis, perante cada caso concreto, a fim de cumprir o dever de adotar a solução mais adequada à satisfação da finalidade legal, quando, por força da fluidez das expressões da lei ou da liberdade conferida no mandamento, dela não se possa extrair objetivamente, uma solução unívoca para a situação vertente. ${ }^{28}$

Assim, é certo que todos os atos da Administração deverão seguir os princípios estabelecidos pelo artigo 37 da Constituição Federal e, sobretudo, hão de se pautar pela finalidade e pelo interesse público. Outrossim, a finalidade deve ser privilegiada em virtude da acepção dirigente com a qual se afigura o Estado brasileiro, isto é, com um nítido viés de promoção do bem-estar e de justiça social.

${ }^{27}$ MELLO, Celso Antônio Bandeira de. Curso de direito administrativo. 18. ed. São Paulo: Malheiros, 2005. p. 399.

${ }^{28}$ MELLO, Celso Bandeira de. Discricionariedade e controle jurisdicional. 2. ed. São Paulo: Malheiros, 2006. p. 48. 
Todo modo, embora a qualificação e configuração do que vem a ser o verdadeiro interesse público possa comportar uma determinada margem de juízo discricionário, a finalidade do ato e da política pública é sempre vinculada, eis que o que se deve perseguir é sempre o interesse público. Assim, não há como se desviar o foco das políticas públicas de tal norte - sempre vinculado, como dito -, zelando-se, dessa feita, pelo cumprimento dos mandamentos constitucionais socializantes já descritos.

\section{0 problema histórico da discricionariedade: da constituição às políticas públicas}

Como é sabido, o Estado Absolutista representou um momento histórico em que os monarcas detinham total controle do poder político, enfeixando em sua própria figura ou na figura de divindades a fonte de seus poderes. Diante disso, a atividade administrativa não encontrava qualquer entrave, visto não existir, ainda, qualquer manifestação das técnicas de controle dos atos estatais que mais tarde se desenvolveriam. Luiz Henrique Cademartori assinala que:

Foi nessa primeira etapa da história que surgiu o chamado Estado de Polícia, sob a égide das monarquias absolutistas. Neste âmbito, o direito do rei para administrar era quase ilimitado, até porque não existia uma divisão de poderes autônomos para separar as funções estatais, estando todas elas, e a própria idéia de Estado, fundidas na pessoa do monarca. Somavam-se a isso, vários princípios consuetudinários legitimadores como o regis voluntas supremas (a vontade do rei é a lei suprema); quod principi placuit legis habet vigorem (aquilo que agrada ao príncipe tem força de lei) ou the king can do not wrong (o rei não pode errar). ${ }^{29}$

Bem de ver que tal cenário acarretava um modelo estatal em que as esferas do público e do privado não apresentavam uma linha divisória nítida, uma vez que o monarca personificava em si todo o organismo político.

${ }^{29}$ CADEMARTORI, Luiz Henrique Urquhart. Discricionariedade administrativa no estado constitucional de direito. Curitiba: Juruá, 2006. p. 37. 
Mais tarde, com o advento do Estado de direito de cunho notadamente liberal - caracterizado por uma atuação social mínima -, a Administração ainda estava galgada em um modelo em que poderia fazer não apenas o que a lei autorizasse, mas também tudo aquilo que por ela não fosse vedado. Sendo assim:

A discricionariedade era a regra geral de ação administrativa em termos de desempenho com livre autonomia em qualquer âmbito não regulado por lei, agindo no espaço livre deixado por ela.

Afirma-se que, nesse caso, a discricionariedade era encarada não como um poder jurídico e sim, como um poder político. Isto também se deve ao fato de que, ainda nesse século, o Estado conservava a sua dupla personalidade, herdeira do absolutismo, do jus politiae, (personalidade de Direito Público) que lhe dava um poder discricionário imune a qualquer controle judicial e a personalidade de Direito Civil (direito privado) de atuação controlável pelo judiciário. ${ }^{30}$

É de se ressaltar, por certo, que embora houvesse uma divisão de poderes políticos a fim de se eliminar a arbitrariedade no âmbito estatal, a supremacia legislativa não encontrava óbices para sua atuação, podendo-se legislar livremente em confronto com valores, direitos e garantias já proclamados, eis que, de fato, o Poder Legislativo detinha um alto grau de discricionariedade e liberdade de atuação.

No entanto, no momento em que o Estado toma para si a direção da sociedade em torno de objetivos notadamente de promoção social, edifica-se uma base comum que tende a alicerçar toda conduta do Estado em consonância com as finalidades erigidas pelo próprio ente estatal (in casu, na Constituição). Essa postura dirigente - sobretudo no âmbito social, como se tem no já discutido Estado Social -, acaba por induzir uma vinculação de toda atuação estatal aos fins estabelecidos, de tal feita que:

O administrador não tem discricionariedade para deliberar sobre a oportunidade e conveniência de implementação de políticas públicas discriminadas na ordem social

\footnotetext{
${ }^{30}$ CADEMARTORI, Luiz Henrique Urquhart. Discricionariedade administrativa no estado constitucional de direito. Curitiba: Juruá, 2006. p. 50.
} 
constitucional, pois tal restou deliberado pelo Constituinte e pelo legislador que elaborou as normas de integração. ${ }^{31}$

\section{Conclusão}

De fato, o que se extrai da presente análise é que as dúvidas sobre essa margem de abertura (discricionariedade) deixada ao administrador na formulação e implementação de políticas públicas, poderão e deverão ter sua análise realizada em função dos mandamentos constitucionais dirigentes no âmbito social, garantindo-se a implementação de tais políticas sempre que se vislumbrar, caso a caso, a adequação proporcional entre a atuação estatal e as finalidades constitucionalmente preconcebidas.

Caberá, então, aos órgãos de controle social - em sentido amplo, a abranger o próprio controle interno Executivo, o Legislativo, o Judiciário, o Ministério Público e os demais integrantes da sociedade civil - analisar as posturas e ações estatais no sentido de se concretizar a normativa constitucional - por meio da implementação de políticas públicas - e, bem assim, controlar a legitimidade da Administração, de forma a contrastar a ação administrativa com a finalidade constitucional e com os princípios jurídicos atinentes à Administração, a fim de que a almejada ordem social constitucional seja concretizada.

\section{Fundamental rights: from the constitution to the public policies}

\section{Abstract}

The present work intends to analyze the concretion of the fundamental rights - mainly the social ones -, constitutionally assured, by the implementation of public policies. For such, an historical view is used to subsidize the normativity and social effectiveness of the fundamental rights, guiding - through a historical

${ }^{31}$ FRISCHEISEN, Luiza Cristina Fonseca. Políticas públicas: a responsabilidade do administrador e o ministério público. São Paulo: M. Limonad, 2000. p. 95. 
analysis of the issue - to a State that works by positive acts, as a form to reach a regular social order, whose leading position, in this framework, is extracted from the Constitution.

Keywords: Fundamental rights. Constitution. Public policies.

\section{Referências}

BONAVIDES, Paulo. Curso de direito constitucional. 18. ed. São Paulo: Malheiros, 2006.

BUCCI, Maria Paula Dallari. Direito administrativo e políticas públicas. São Paulo: Saraiva, 2002.

CADEMARTORI, Luiz Henrique Urquhart. Discricionariedade administrativa no estado constitucional de direito. Curitiba: Juruá, 2006.

COMPARATO, Fábio Konder. Ensaio sobre o juízo de constitucionalidade de políticas públicas. Revista dos Tribunais, São Paulo, ano 86, v. 737, p. 11-22, mar. 1997.

FREIRE JÚNIOR, Américo Bedê. O controle judicial de políticas públicas. São Paulo: Revista dos Tribunais, 2005.

FRISCHEISEN, Luiza Cristina Fonseca. Políticas públicas: a responsabilidade do administrador e o ministério público. São Paulo: M. Limonad, 2000.

MELLO, Celso Antônio Bandeira de. Curso de direito administrativo. 18. ed. São Paulo: Malheiros, 2005.

MELLO, Celso Antônio Bandeira de. Discricionariedade e controle jurisdicional. 2. ed. São Paulo: Malheiros, 2006.

MENDES, Gilmar Ferreira. Direitos fundamentais e controle de constitucionalidade. 3. ed. São Paulo: Saraiva, 2004.

PIZZOLATTI, Rômulo. O controle jurisdicional do mérito na atividade administrativa. 2001. Tese (Doutorado)-Centro de Ciências Jurídicas, Universidade Federal de Santa Catarina, Florianópolis, 2001. 

82 Rev. Bras. de Políticas Públicas, Brasília, v. 1, n. 1, p. 65-82, jan./jun. 2011
Bruno Santos Cunha

SARLET, Ingo Wolfgang. A eficácia dos direitos fundamentais. 3. ed. rev. atual. ampl. Porto Alegre: Livraria do Advogado, 2003.

SILVA, José Afonso da. Curso de direito constitucional positivo. 22. ed. rev. atual. São Paulo: Malheiros, 2003. 